\title{
Slug Characteristics of Polymer Particles in a Fluidized Bed with Different Distributors
}

\author{
See Hoon Lee, Dong Hyun Lee and Sang Done Kim \\ Department of Chemical Engineering and Energy \& Environment Research Center \\ Korea Advanced Institute of Science and Technology, Daejeon 305-701, Korea \\ (Received 9 February 2001 accepted 16 March 2001)
}

\begin{abstract}
Pressure fluctuations in a fluidized bed (0.38 m-I.D. $\times 4.4 \mathrm{~m}$-high) of 1.23-mm polymer particles (LLDPE) were measured with different distributors. Slug characteristics (slug frequency and slug rising velocity) were determined by analyzing pressure fluctuations in the bed. The effects of gas velocity $(0.6-1.2 \mathrm{~m} / \mathrm{s}$ ) and distributor geometry (opening area ratio, number of orifices and distributor types) on the slug characteristics were determined. The slug frequency decreases slightly with increasing gas velocity. However, slug rising velocity increases linearly with increasing excess fluidization velocity regardless of the distributors used.
\end{abstract}

Key words: Slug Frequency, Slug Rising Velocity, Polymer Particles, Distributor Types

\section{INTRODUCTION}

Fluidized beds have been used widely in industrial processes involving combustors and FCC regenerators, to name but a few. A fluidized bed reactor can be utilized for the gas-phase polymerization of ordinary polymer resin such as linear-low-density-polyethylene (LLDPE) since no separation is needed between products and catalysts. In fluidized beds for polymer production, agglomeration of particles occurs due to static electricity that comes from friction of particles to particles and particles to wall; hence sintering and softening of particles occur [Boland and Geldart, 1971; Kim and Han, 1999]. The fluidizing behavior is shifted to channeling and increases in pressure drop in the beds [Davidson and Harrison, 1977; Geldart, 1986]. Therefore, uniformity of fluidization may affect particle mixing and distribution of bubbles or slugs in the beds. This non-uniformity may cause a dead zone and hotspots and consequent unstable operation of the polymerization process.

In producing polymer materials in a fluidized bed reactor, bubble size usually increases rapidly to become slugs with increasing gas velocity. Therefore, it is very important to have knowledge of the slugging characteristics in a fluidized bed for a polymerization process. With different gas distributors, information on both slug frequency and slug rising velocity can provide the optimum operating conditions for polymerization reaction in a fluidized bed reactor [Turton and Clark, 1989]. Many studies have been reported on the slug characteristics by measuring the pressure fluctuations [Satija and Fan, 1985; Noordergraaf et al., 1987; Lee and Kim, 1988; Baeyens and Geldart, 1974; Broadhurst and Becker, 1975] and video movies [Luca et al., 1992] in the beds. However, the majority of studies on slugging characteristics have been conducted in beds of relatively fine particles [Fan et al., 1983; Dimattia et al., 1997].

In the present study, the effects of gas velocity $(0.6-1.2 \mathrm{~m} / \mathrm{s})$ and distributor geometry (opening area ratio, number of orifices and

To whom correspondence should be addressed.

E-mail: kimsd@kaist.ac.kr

distributor types) on the slug characteristics have been determined.

\section{EXPERIMENAL}

\section{Experimental Apparatus}

Experiments were carried out in a fluidized bed $(0.38 \mathrm{~m}-\mathrm{ID} \times 4.3$

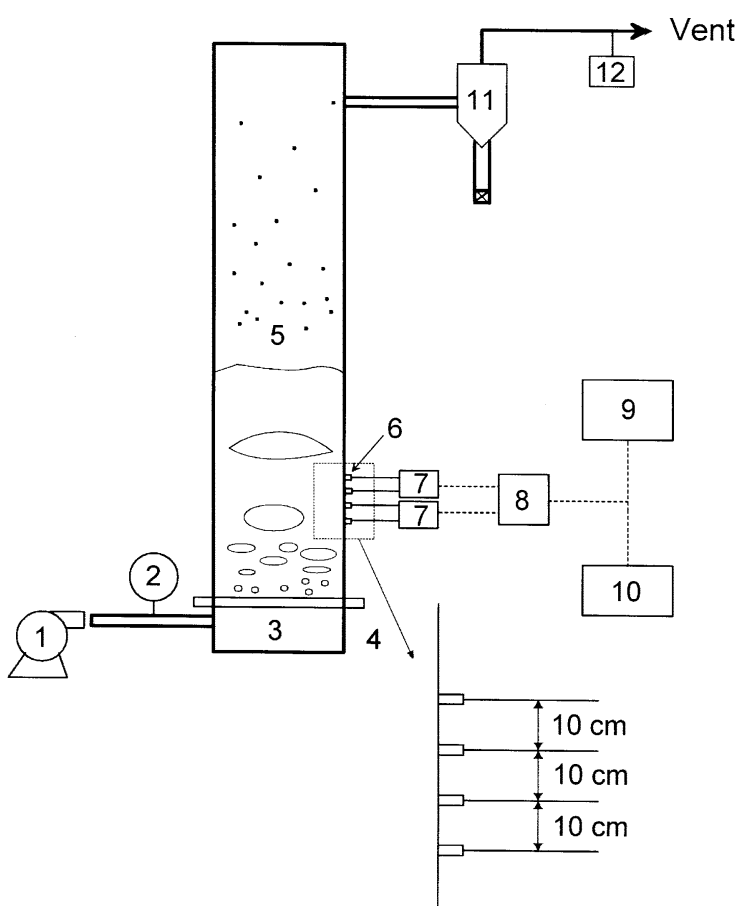

Fig. 1. Schematic diagram of experimental apparatus.

1. Blower

2. Pressure gauge

3. Air chamber

4. Distributor

5. Bed

6. Pressure tap
7. Pressure transducer

8. A/D converter

9. PC

10. Oscilloscope

11. Cyclone

12. Air flow meter 
Table 1. Distributor properties of this experiment

\begin{tabular}{cllcc}
\hline \hline $\begin{array}{c}\text { Distributor } \\
\text { number }\end{array}$ & Type & $\begin{array}{c}\text { Hole size } \\
{[\mathrm{mm}]}\end{array}$ & Number & $\begin{array}{c}\text { Opening area } \\
\text { ratio [\%] }\end{array}$ \\
\hline 1 & Perforated & 6.35 & 290 & 8 \\
2 & Perforated & 3 & 207 & 1.3 \\
3 & Perforated & 5 & 76 & 1.3 \\
4 & Bubble cap & 4 & $30(\times 4)$ & 1.3 \\
\hline
\end{tabular}

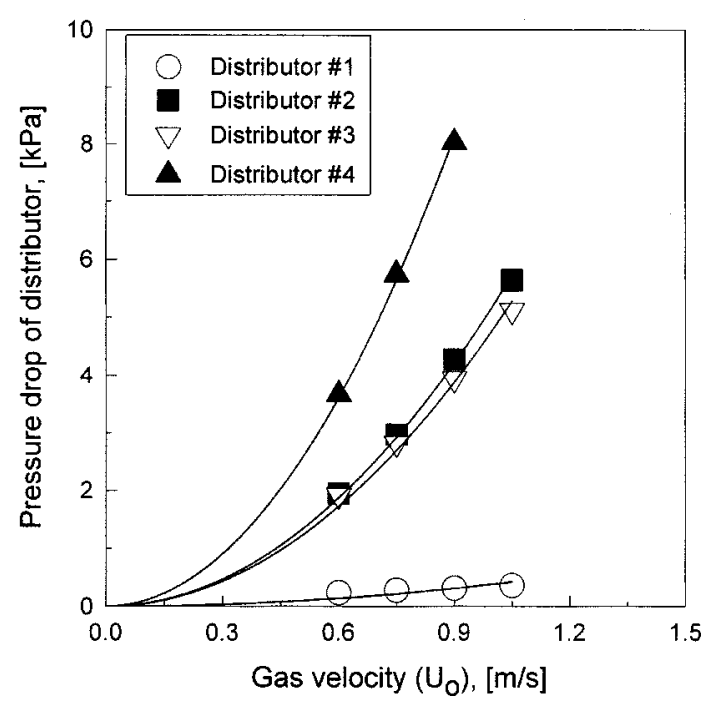

Fig. 2. Effect of excess fluidization velocity on pressure drop across the distributors.

m-high) made of a transparent Plexiglas column as shown schematically in Fig. 1. Air flow rates were measured by a flow meter (Tri-Sense Model No. 37000-00, Cole-Parmer Co.) in the range of 0-1.5 m/s. Four different types of gas distributors were employed. In cases of perforated distributors, 400-mesh screen was covered on the surface of a distributor to prevent particle weeping from the bed to the plenum chamber. Details of four different distributors used in this study are shown in Table 1 and Fig. 2. The particle used in this study was $1.23 \mathrm{~mm}$ LLDPE particle with density of $919 \mathrm{~kg} /$ $\mathrm{m}^{3}$. Pressure taps were mounted flush with the wall of the column at $0.1-\mathrm{m}$ height intervals from $0.55 \mathrm{~m}$ above the distributor, and the taps were connected to differential pressure transducers. The opening of pressure taps was covered with a screen (400-mesh) to prevent particle leaking from the bed. The other side of the pressure taps was connected to one of the input channels of the differential pressure transducer (Validyne P306D) in the range of 0-350 mm$\mathrm{H}_{2} \mathrm{O}$ from which an output voltage that was proportional to pressure difference between the two channels was obtained. Transducer signals were monitored by an oscilloscope, and processed by a personal computer at a sampling frequency of $100 \mathrm{~Hz}$ for $60 \mathrm{~s}$.

\section{Slug Measurements}

Typical pressure fluctuation signals are shown in Fig. 3 in which the signals can be divided into emulsion and slug phases by a reference value. In the smoothed signals, there were time delays between the signals from the upper and lower pressure taps. The slug rising velocity and its mean value were calculated by the following equations, respectively.

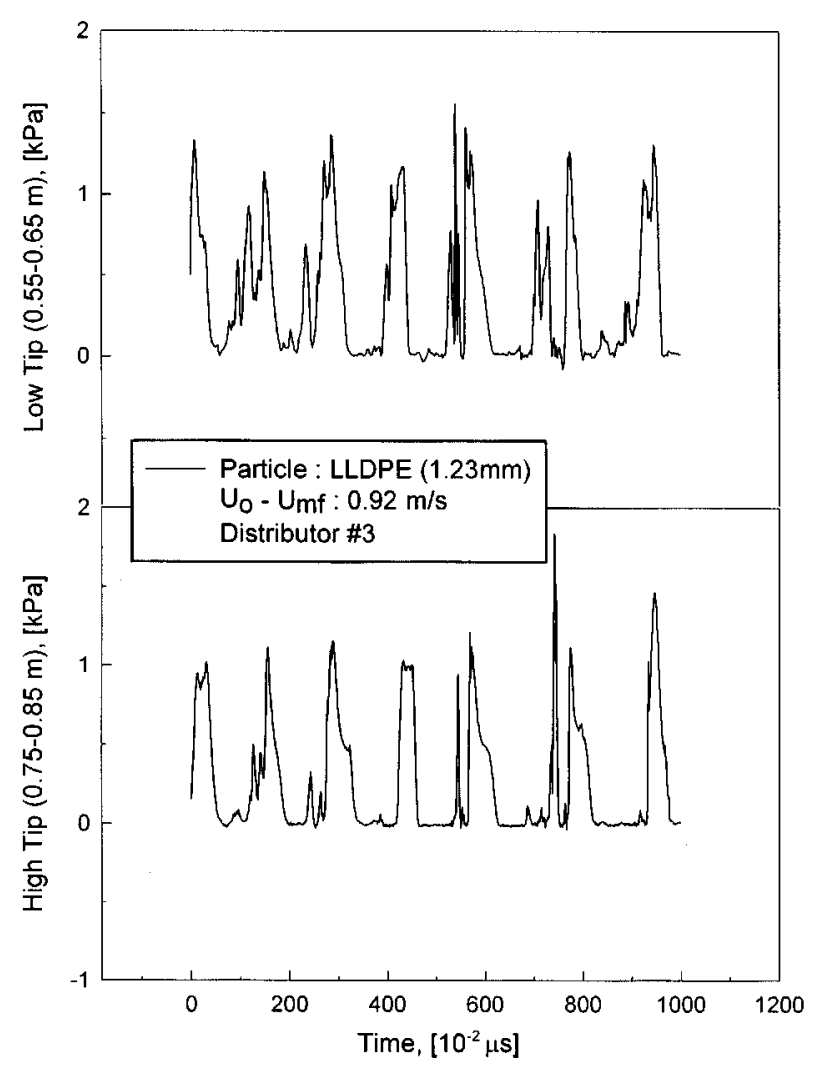

Fig. 3. Typical response signals in the lower and upper of pressure transducer.

$$
\begin{aligned}
& \mathrm{U}_{s i}=\frac{\text { distance between two taps }}{\mathrm{T}_{i}} \\
& \mathrm{U}_{S}=\frac{1}{\mathrm{n}_{i}} \sum_{i}^{n} \mathrm{U}_{s i}
\end{aligned}
$$

The slug frequency was calculated by

$$
\mathrm{f}=\frac{\mathrm{n}(\text { number of slugs })}{\mathrm{T}(\text { total sampling time })}
$$

\section{RESULTS AND DISCUSSION}

The effect of excess fluidization velocity $\left(\mathrm{U}_{o}-\mathrm{U}_{m f}\right)$ on the average slug frequency using the perforated plate (hole size $=5 \mathrm{~mm}$ ) is shown in Fig. 4. The average slug frequency decreases slightly with increasing excess fluidization velocity as reported by previous studies [Shichun et al., 1985; Satija and Fan, 1985]. However, Baeyens and Gedart [1974] and Brodhurst et al. [1983] reported that the excess fluidization velocity does not affect slug frequency. The calculated slug frequencies from the correlation equations proposed by previous studies cannot predict the data of the present study due to the difference of powder properties employed such as the Geldart A and B particles [Baeyans and Geldart, 1974; Brodhurst et al., 1983; Shichun et al., 1985]. Since Satija and Fan [1985] used Geldart D particles, their slug characteristics are different from the present LLDPE particles.

The effect of excess fluidization velocity on the average slug rising velocity is shown in Fig. 5 with the calculated values. As can be 


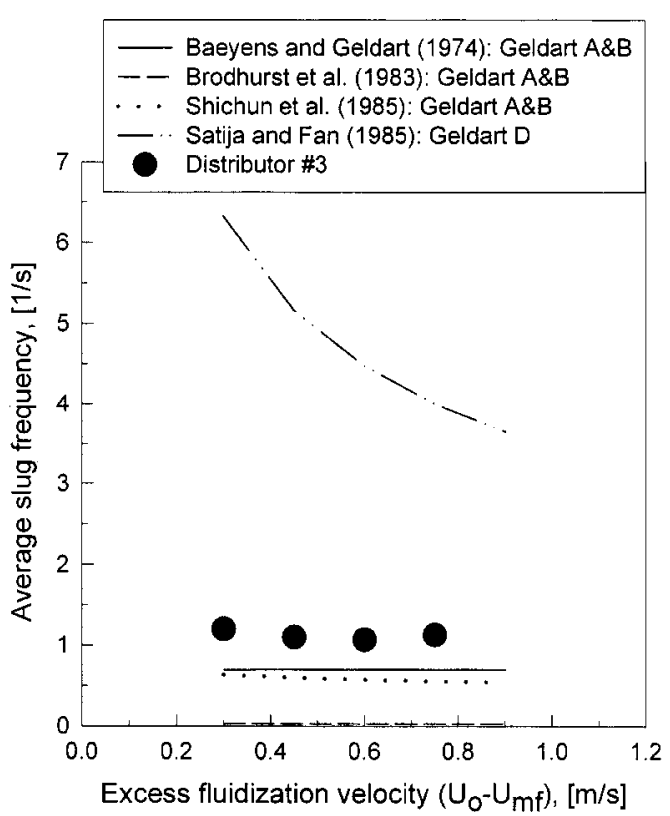

Fig. 4. Effect of excess fluidization velocity on average slug frequency.

seen, the average slug rising velocity increases with increasing the excess fluidization velocity. Most of the reported studies related the average slug rising velocity to the excess fluidization velocity as shown:

$$
\mathrm{U}_{s}=\mathrm{k}_{1}\left(\mathrm{U}_{o}-\mathrm{U}_{m f}\right)+\mathrm{k}_{2} \sqrt{\mathrm{gD}_{C}}
$$

where constants, $\mathrm{k}_{1}$ and $\mathrm{k}_{2}$ varied with particle properties.

As can be seen in Fig. 5, the calculated values from Eq. (4) overestimate the experimental values.

The effect of distributor type (Table 1) such as the perforated plate and the bubble cap types on the slug characteristics is shown in Fig. 6. As can be seen, the average slug frequencies decrease with increasing the excess fluidization velocity with distributors \#3 and 4

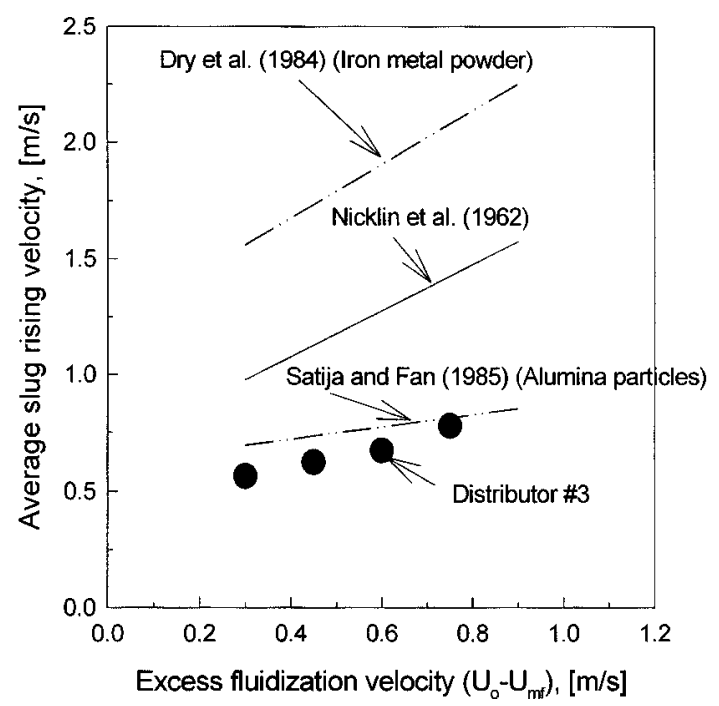

Fig. 5. Effect of excess fluidization velocity on average slug rising velocity.

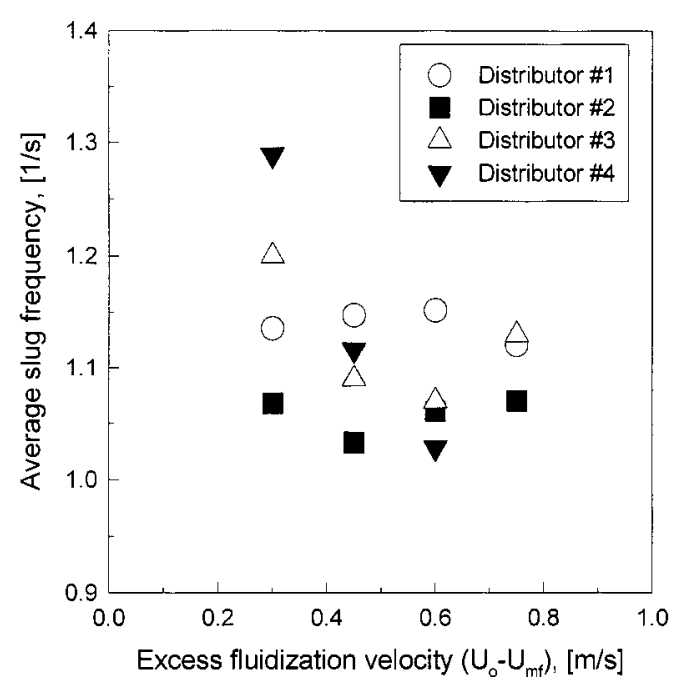

Fig. 6. Effect of excess fluidization velocity on average slug frequency in various distributors.

(Table 1). However, the average slug frequency is similar to that of distributor \#2. At lower excess fluidization velocities with the same opening area ratio, the distributor \#2 produces less slug frequency than that of the other distributors since distributor \#2 has many hole numbers and close pitch. Wen and King [1980] reported that bubbles formed and then immediately coalesced because of very close orifice pitch. They proposed the minimum pitch length as follows:

$$
\mathrm{L}_{p} \leq 0.01 \mathrm{~d}_{o r}+\left[\frac{\mathrm{U}_{o}-\mathrm{U}_{m f}}{3010 \mathrm{~N}_{o r}}\right]^{\frac{1}{\left(0.024 d_{p}^{-0.205}\right)}}
$$

The minimum pitch length calculated by the above equation is 26 $\mathrm{mm}$ but that of distributor \#2 is $24 \mathrm{~mm}$. Therefore, slug can be formed easily at lower gas velocities due to bubble coalescence. The average slug frequency of distributor \#4 is higher than that of the perforated plate distributors (\#2 and \#3) at the excess gas velocity of $0.3 \mathrm{~m} / \mathrm{s}$ since slug formation with the bubble cap distributor occurs less than that with the perforated plate distributor. Slug coalescence occurs frequently, and consequent decrease in slug frequency with increasing gas velocity due to the negligible jetting effect and large bubble size increases with increasing gas velocity in the distributor \#4 [Kim et al., 1997].

The effect of excess fluidization velocity on the average slug rising velocity is shown in Fig. 7 where the average slug rising velocity increases with increasing gas velocity. However, the average slug rising velocities are similar with the four distributors since the distributor type does not affect slug rising velocity in the bed of LLDPE particles since LLDPE particles produce square-nose type slug in which particles rain continuously through voids in the slug. Therefore, the square-nose type slug is strongly affected by wall effect. Noordergraaf et al. [1987] reported that the slug rising velocity is lower than superficial gas velocity in the square-nose type slug as observed in the present study. These square-nose type slugs grow up above $0.6 \mathrm{~m}$ from the distributor. The obtained slug rising velocity is correlated as

$$
\mathrm{U}_{s}=0.6\left(\mathrm{U}_{o}-\mathrm{U}_{m f}\right)+0.18 \sqrt{\mathrm{gD}_{C}}
$$




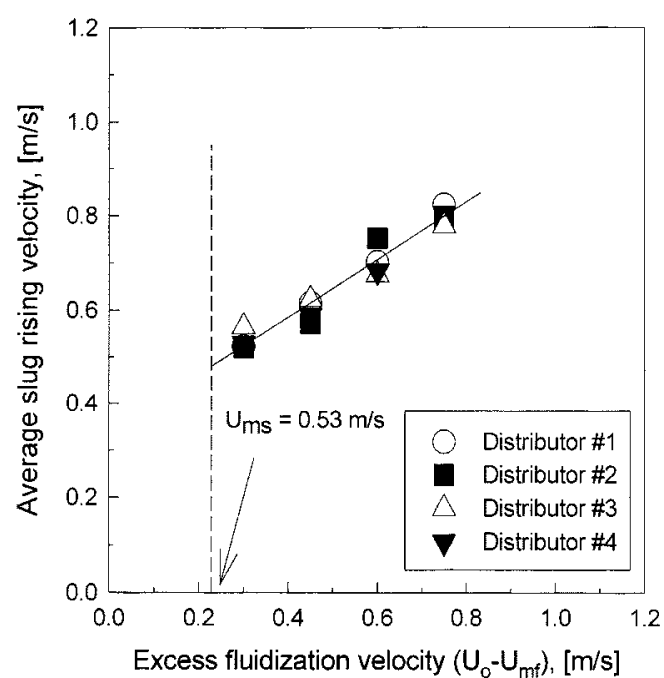

Fig. 7. Effect of excess fluidization velocity on average slug rising velocity in various distributors.

with a correlation coefficient of 0.94 , and the average absolute deviation $(A A D)$ of slug rising velocity of $0.3 \%$.

The number of orifices and orifice size in the distributor affect bubble coalescence and slug formations. For air-water systems, Yamashita and Inoue [1975] introduced a distributor parameter as follows:

$$
\eta_{D}=\left(\frac{\mathrm{L}_{p}}{\mathrm{~d}_{o r}}\right)\left(\frac{\mathrm{N}_{o r}}{\mathrm{D}_{C}^{2}}\right)=\frac{\mathrm{N}_{o r} \mathrm{~L}_{p}}{\mathrm{~d}_{o r} \mathrm{D}_{C}^{2}}
$$

At a given $\mathrm{U}_{o}, \varepsilon_{g}$ tends to increase with increasing $\mathrm{L}_{p} / \mathrm{d}_{o r}$, a factor relating to the interaction between neighboring bubbles at injection, or with decreasing $\mathrm{D}_{C}^{2} / \mathrm{N}_{o r}$, a factor controlling the gas flow rate through each holes [Yamashita and Inoue, 1975; Sakata and Miyauchi, 1980]. Tsuchiya and Nakanishi [1992] reported that this lumped parameter could be used for representing the combined effects of the two factors relating to the distributor performance.

Variation of the average slug rising velocity with $\eta_{D}$ at different

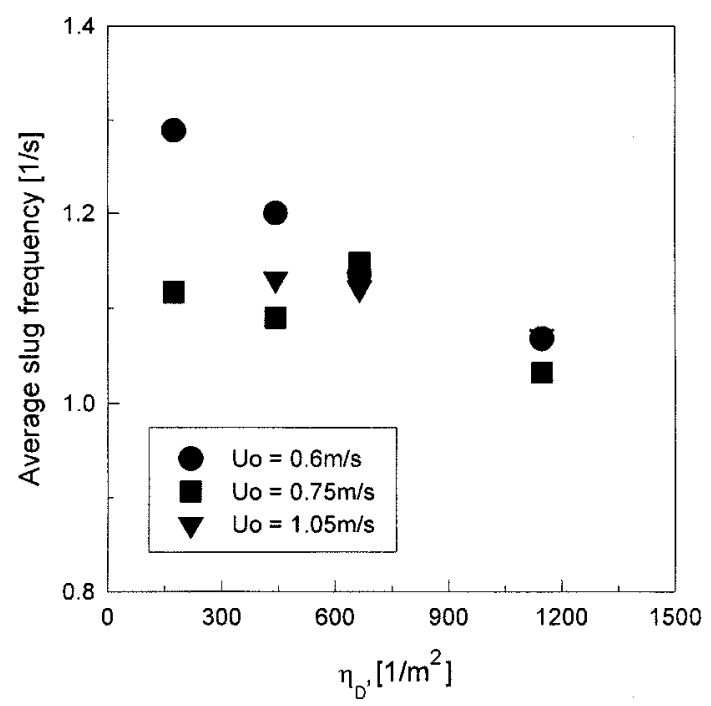

Fig. 8. Effect of $\eta_{D}$ on average slug frequency.

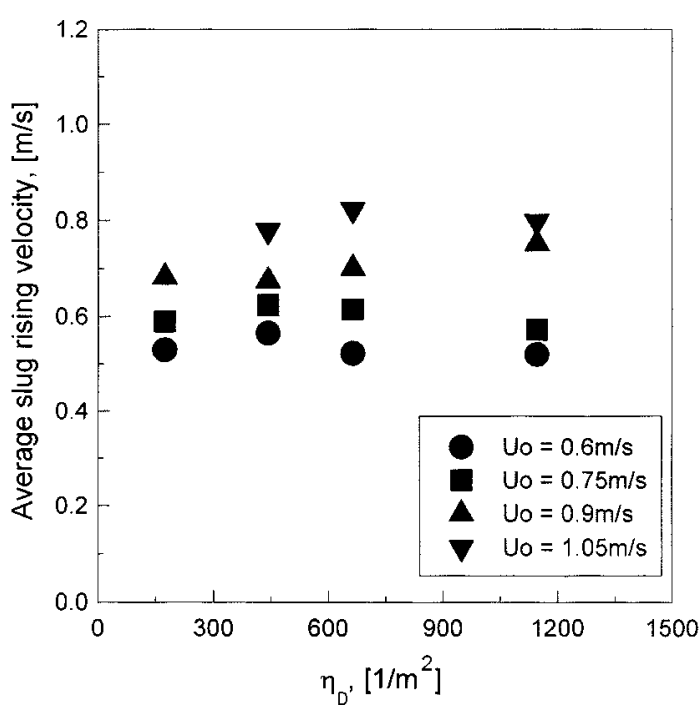

Fig. 9. Effect of $\eta_{D}$ on average slug rising velocity.

excess fluidization velocities is shown in Fig. 8. As can be seen, the average slug frequency decreases with increasing $\eta_{D}$ with perforated plates. The rate of bubble coalescence increases with increasing $\eta_{D}$ due to the increase of number of bubbles generated from the distributor and consequent increase in slug size with increasing $\eta_{D}$. However, slug frequency decreases with increasing $\eta_{D}$.

The effect of $\eta_{D}$ on the average slug rising velocity at different excess fluidization velocities is shown in Fig. 9. As can be seen, the average slug rising velocity is similar to the variation of $\eta_{D}$ for all four distributors due to the wall effect.

\section{CONCLUSION}

The effects of excess fluidization velocity and distributor geometry (opening area ratio, number of orifices and distributor types) on slug characteristics have been determined in a fluidized bed of LLDPE powders. Slug frequency decreases with increasing gas velocity with distributors \# 3 and \#4. However, the average slug frequency is similar with increasing gas velocity with distributor \#2. Slug rising velocity increases with increasing gas velocity with the four distributors. Slug rising velocity has been correlated as

$$
\mathrm{U}_{s}=0.6\left(\mathrm{U}_{o}-\mathrm{U}_{m f}\right)+0.18 \sqrt{\mathrm{gD}_{C}}
$$

The effect of distributor geometry on slug frequency is pronounced but slug rising velocity is similar with the four different distributors due to the wall effect.

\section{ACKNOWLEDGEMENT}

The authors are grateful to the aid of financial support for research from the Samsung General Chemical Co., and one of the authors (D. H. Lee) wishes to thank the Ministry of Education for partial financial support (BK-21 Project).

\section{NOMENCLATURE}

$\mathrm{D}_{C} \quad$ : column diameter $[\mathrm{m}]$ 
$\mathrm{d}_{o r} \quad$ : diameter of orifice $[\mathrm{mm}]$

$\mathrm{d}_{p} \quad$ : particle size [mm]

f : point slug frequency $\left[\mathrm{s}^{-1}\right]$

$\mathrm{k}_{1}, \mathrm{k}_{2}$ : constant [-]

$\mathrm{L}_{p} \quad$ : pitch length [mm]

$\mathrm{N}_{o r}$ : number of orifices [-]

$\mathrm{n}$ : number of slugs [-]

$\mathrm{T} \quad$ : total sampling time [s]

$\mathrm{T}_{i} \quad$ : phase shift between two corresponding slug signals [s]

$\mathrm{U}_{o} \quad$ : superficial gas velocity $[\mathrm{m} / \mathrm{s}]$

$\mathrm{U}_{m f}:$ minimum fluidization velocity $[\mathrm{m} / \mathrm{s}]$

$\mathrm{U}_{s} \quad$ : mean slug rising velocity $[\mathrm{m} / \mathrm{s}]$

$\mathrm{U}_{s i} \quad$ : instantanious slug rising velocity $[\mathrm{m} / \mathrm{s}]$

\section{Greek Letters}

$\varepsilon_{g} \quad$ : gas holdup [-]

$\eta_{D} \quad$ : distributor parameter defined by Eq. (7) $\left[1 / \mathrm{m}^{2}\right]$

\section{REFERENCES}

Baeyens, J. and Geldart, D., "An Investigation into Slugging Fluidized Beds,' Chem. Eng. Sci., 29, 255 (1974).

Boland, D. and Geldart, D., "Electrostatic Charging in Gas Fluidised Beds,' Powder Technol., 5, 289 (1971).

Brodhurst, T. E. and Becker, H. A., "Measurement and Spectral Analysis of Pressure Fluctuations in Slugging Beds,' Fluidization Technology, D. L. Keairns, Ed., I, 63, Hemisphere Pub., Washington, DC (1976).

Davidson, J. F. and Harrison, D., "Fluidization,' Academic Press, New York (1977).

De Luca, L., Di Felico, R. and Foscolo, P. U., "Slugging Behavior of Fluidized Beds of Large Particles,' Powder Technol., 69, 171 (1992).

Dimattia, D. G., Amyotte, P. R. and Hamdullahpur, F., "Slugging Characteristics of Group D Particles in Fluidized Beds,' Can. J. Chem. Eng., 75, 452 (1997).

Fan, L. T., Ho, T. C. and Walawender, W. P., "Measurements of the Rise
Velocities of Bubbles, Slugs and Pressure Waves in a Gas-Solid Fluidized Bed Using Pressure Fluctuation,' AIChE J., 29, 33 (1983).

Geldart, D., "Gas Fluidization Technology,' $1^{\text {st }}$ ed., John Wiley \& Sons Ltd. (1986).

Kim, G. J., Kim, J. L., Choi, J. H. and Kim, S. D., "Design of Distributor in Fluidized Bed,' Chem. Ind. and Technol., 15, 32 (1997).

Kim, S. H. and Han, G. Y., "Flow Stability of Circulating Fluidized Bed with Polymeric Particles,' Korean J. Chem. Eng., 37, 191 (1999).

Kunii, D. and Levenspiel, O., "Fluidization Engineering,' $2^{\text {nd }}$ ed., Butterworth-Heinemann (1991).

Lee, G. S. and Kim, S. D., "Rise Velocity of Slugs and Voids in Slugging and Turbulent Fluidized Beds,' Korean J. Chem. Eng., 6, 15 (1989).

Noordergraaf, I. W., Van Dijk, A. and Van Den Bleek, C. M., "Fluidization and Slugging in Large-Particle Systems,' Powder Technol., 52, 59 (1987).

Sakata, M. and Miyauchi, T., "Transition of the Uniform Bubble Flow Regime to the Turbulent Recirculation Bubble Floe Regime in a Bubble Column,' Kagaku Kokagu Ronbunshu, 6, 428 (1980).

Shichun, C., Heling, Z. and Feichen, J., "A Study of Hydrodynamics Behavior of the Slugging Fluidized Bed,' Fluidization, M. Kwauk and D. Kunii, Eds., Elsevier, Amsterdam, 75 (1985).

Satija, S. and Fan, L. S., "Characteristics of Slugging Regime and Transition to Turbulent Regime for Fluidized Beds of Large Coarse Particles,' AIChE J., 31, 1554 (1985).

Tsuchiya, K. and Nakanishi, O., "Gas Holdup Behavior in a Tall Bubble Column with Perforated Plate Distributors,' Chem. Eng. Sci., 47, 3347 (1992).

Turton, R. and Clark, N. N., "Interpreting Probe Signals from Fluidized Beds,' Powder Technol., 59, 117 (1989).

Wen, C. Y. and King, D. F., “Distributor Design,' Proc. DOE/WVU Conference on Fluidized-bed Combustion System Design and Operation, 164 (1980).

Yamashita, F. and Inoue, H., "Gas Holdup in Bubble Columns,' J. Chem. Eng. Japan, 8, 334 (1975). 